\title{
Analysis of Internet Finance based on the Long Tail Theory: the Financing of Small and Micro Enterprises For Example
}

\author{
Lin Jun ${ }^{1, a,{ }^{*}}$, Yan Xiao-qing ${ }^{1, b}$ \\ ${ }^{1}$ Business school of Ningbo University, Ningbo, Zhejiang, China \\ axiaochen7935@qq.com, byanxiaoqing@nbu.edu.cn \\ ${ }^{*}$ Corresponding author
}

\begin{abstract}
Based on the long tail theory,this paper analyzes the internal logic betweeninternet finance and the financing problems of small and micro enterprises.This paper illustrates that small and micro enterprises have distinct long-tailed effect on internet finance through the features of long tail market and Pareto distribution,their demand of financing make up a long tail market which will be the blue ocean market for internet finance. Internet finance has advantage in solving the financing problems of small and micro enterprises and will be helpful to promote the development of inclusive finance.
\end{abstract}

Key words:the principle of $80 / 20$; the long tail theory; internet finance; small and micro enterprises

\section{基于长尾理论的互联网金融分析--以小微企业贷款为例}

\author{
林君 ${ }^{1, a,{ }^{*}}$, 燕小青 ${ }^{1, b}$ \\ ${ }^{1}$ 宁波大学商学院, 宁波, 浙江, 中国 \\ axiaochen7935@qq.com, byanxiaoqing@nbu. edu.cn \\ *通讯作者
}

中文摘要. 文章基于长尾理论探讨互联网金 融解决小微企业融资难的内在逻辑, 通过长 尾市场特征以及帕累托分布证明小微企业对 互联网金融的长尾效应尤为显著, 其资金需 求构成的长尾市场将会成为互联网金融发展 更加广阔的 “蓝海” 市场, 而互联网金融又 在利用自身优势解决小微企业信贷难的基础 上, 实现了普惠金融的发展。

关键词：二八定律; 长尾理论; 互联网金融; 小微企业

\section{1. 引言}

传统商业银行是帕累托二八定律的忠实 拥护者, 在经营管理中强调优质客户管理, 并认为 $20 \%$ 的优质客户能带来 $80 \%$ 的利润。 这些优质客户主要包括国有企事业单位和其 他大中型企业, 具有单次贷款额大、违约风 险低点等特点。商业银行的 “嫌贫爱富” 由 其商业性决定：商业银行与小微企业之间存 在较高的信息不对称，向小微企业贷款交易 成本高、收益小、风险大等特点, 不符合银 行安全性、盈利性原则。据统计 $90 \%$ 的小微 
企业存在融资难题, 小微企业信贷可得性仅 为 $46.2 \%$ 。然而, 数量庞大的小微企业对我 国的经济发展、社会稳定十分重要: 当前我 国有小微企业 5606 万户，占企业总数的 $94.15 \%$ 。小微企业解决了我国 1.5 亿人口的 就业问题, 贡献了 $60 \%$ 的 GDP 和 50\%的税收。 小微企业的贷款满足程度不高, 金融需求亟 待解决。

长尾理论与二八定律相对应, 长尾理论 认为在一定条件下, $80 \%$ 冷门产品共同占据 的市场份额可以和 $20 \%$ 的热销产品所占据的 市场份额相匹敌，被忽视的 $80 \%$ 也可以带来 巨大利润。长尾理论为互联网金融的存在奠 定了基础, 为互联网金融支持小微企业提供 了理论支持。

\section{2. 互联网金融长尾市场的分析}

\section{1 基于长尾理论特征分析}

长尾理论主要有以下特征：第一，尾部 的冷门产品数量接近总数的 $80 \%$ (如图 1 所 示), 并且还在快速增长, 这是长尾理论的基 础。单个冷门产品的效益有限, 而总量足够 大的冷门产品的效益全部加总, 就能形成规 模, 甚至超过热门产品的效益。第二, 随着 互联网的广泛覆盖和应用, 人们可以通过网 络搜索快速找到自己需要的事物, 关注冷门 产品的成本极低。第三, 长尾理论的头尾部 是动态变化的。当原本的热门产品不再受到 人们追捧时, 它可能转变为冷门产品, 而原 本的冷门产品也可能因为某种原因开始受欢 迎, 从而转变为热门产品 (如图 2 所示)。

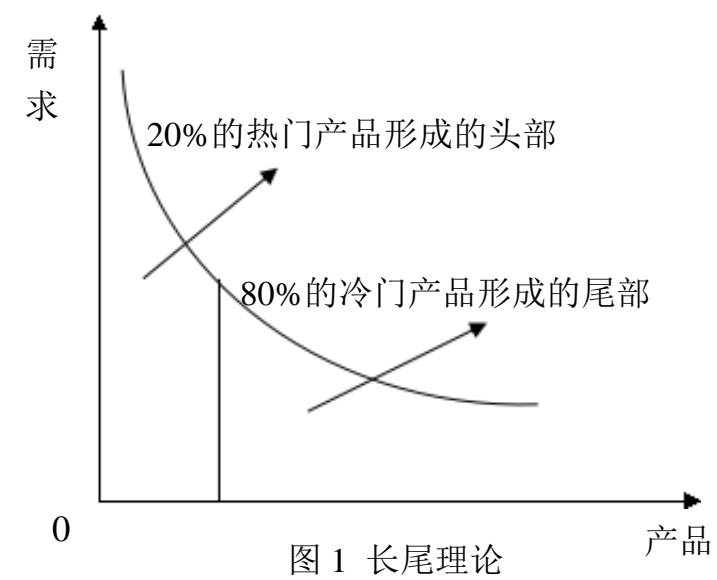

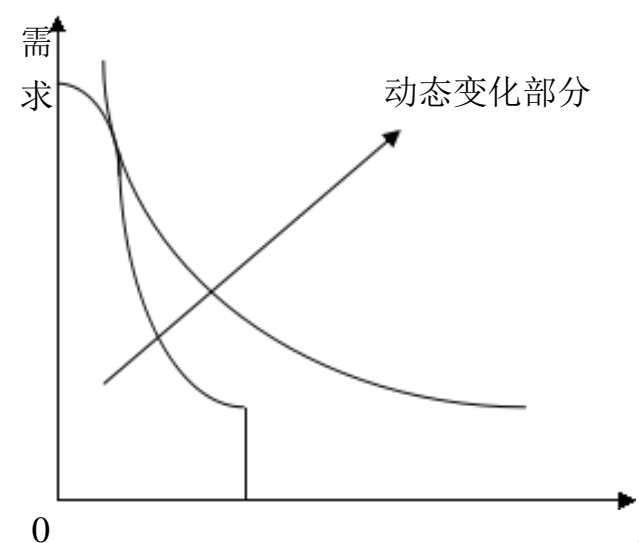

图 2 改进的长尾理论产品

文章选取了 2012 年一季度至 2015 年一 季度的金融机构贷款投向数据（如表 1 所 示)。可以看到, 三年来主要金融机构、小型 农村金融机构对小微企业的贷款稳步增长, 2012 年一季度至今小微企业贷款余额增加了 53\%，高于同时期的企业及其他部门贷款增 速; 小微企业贷款所占比重上升, 从 2012 年 一季度的 $22.81 \%$ 上升至 2015 年一季度的 $24.40 \%$ 。该趋势说明小微企业贷款问题越来 越受到监管部门和金融机构重视。然而，从 小微企业的数目和其贷款比重来看，小微企 业所得贷款依然非常有限：占企业总数 $95 \%$ 的小微企业仅得到了 $25 \%$ 左右的贷款 (如图 3 所示)。

表 1 近三年金融机构贷款投向

\begin{tabular}{|c|c|c|c|}
\hline 时间 & $\begin{array}{c}\text { 小微企业贷 } \\
\text { 款余额（万 } \\
\text { 亿） }\end{array}$ & $\begin{array}{c}\text { 企业及其他部 } \\
\text { 门贷款余额 } \\
\text { (万亿 }\end{array}$ & $\begin{array}{c}\text { 小微企业 } \\
\text { 贷款占比 }\end{array}$ \\
\hline $2012-Q 1$ & 10.38 & 45.51 & $22.81 \%$ \\
\hline $2012-Q 2$ & 10.87 & 47.38 & $22.94 \%$ \\
\hline $2012-Q 3$ & 11.29 & 48.64 & $23.21 \%$ \\
\hline $2012-Q 4$ & 11.58 & 49.78 & $23.26 \%$ \\
\hline $2013-Q 1$ & 11.78 & 51.98 & $22.66 \%$ \\
\hline $2013-Q 2$ & 12.25 & 53.18 & $23.03 \%$ \\
\hline $2013-Q 3$ & 12.82 & 54.26 & $23.63 \%$ \\
\hline $2013-Q 4$ & 13.21 & 55.18 & $23.94 \%$ \\
\hline $2014-Q 1$ & 13.7 & 57.68 & $23.75 \%$ \\
\hline $2014-Q 2$ & 14.17 & 59.44 & $23.84 \%$ \\
\hline $2014-Q 3$ & 14.55 & 60.47 & $24.06 \%$ \\
\hline $2014-Q 4$ & 15.46 & 61.8 & $25.02 \%$ \\
\hline $2015-Q 1$ & 15.89 & 65.11 & $24.40 \%$ \\
\hline
\end{tabular}

数据来源: 中国人民银行 


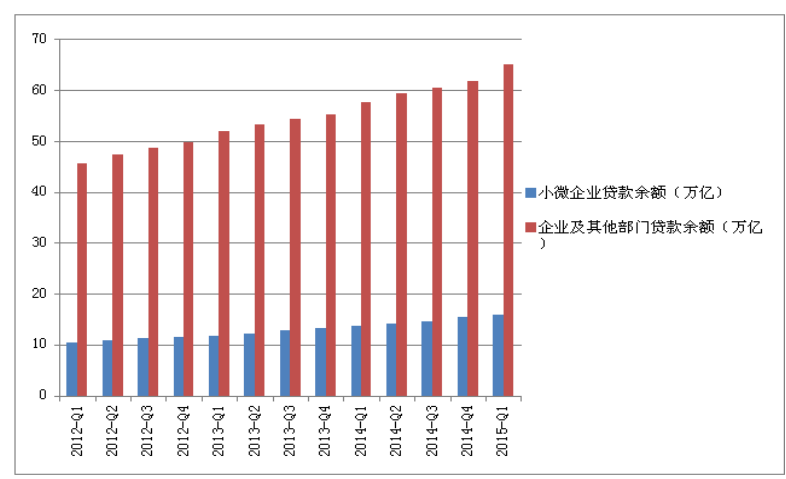

图 3 金融机构贷款投向

将小微企业的现实状况类比至长尾理 论, 小微企业数量庞大, 占全国企业总数的 $94.15 \%$, 并且以每年 $10 \%$ 的速度递增。在互 联网技术支持下, 关注小微企业融资需求的 成本大大降低。虽然单个小微企业的融资需 求较小, 不能和大企业相提并论, 但所有小 微企业的资金需求集结起来会是一笔巨大的 数目。小微企业发展状态好, 扩大生产规模 以后可能会成为大中型企业, 而大中型企业 如若经营不善, 资不抵债, 也可能因变卖资 产, 破产重组成为小微型企业。不难看出, 小微企业具备了安德森长尾理论的特征。融 资需求未得到满足的小微企业是正态分布曲 线的 “尾部”, 长尾理论的长尾。

\section{2 基于帕累托分布分析}

在帕累托分布中, 如果 $\mathrm{X}$ 是一个随机变 量, 则 $X$ 的概率分布:

$$
\mathrm{P}(\mathrm{X}>\mathrm{X})=\left(\frac{X}{x_{\min }}\right)^{-k}
$$

$\mathrm{x}$ 为大于 $\mathrm{x}_{\text {min }}$ 的任意实数, $\mathrm{x}_{\text {min }}$ 是 $\mathrm{X}$ 最小 的可能值 (正数)。 $\mathrm{K}>0$ 时, 帕累托曲线是 所有 $\mathrm{K}$ 与 $\mathrm{x}_{\text {min }}$ 的组合。随着 $\mathrm{x}$ 的不断增加, 事件 $\mathrm{X}>\mathrm{X}$ 发生的概率逐渐变小, 并形成一条 长长的尾巴。

\section{从银行向小微企业发放贷款的角度来}

看：假设对所有小微企业的贷款利率保持一 致, 横轴是有资金需求的小微企业数量, 纵 轴为商业银行发放贷款的收益率, 银行向小 微企业贷款事件发生的概率为 $\mathrm{P}(\mathrm{X}>\mathrm{X})$ 。根 据帕累托分布, 可以得到如图 4 的图象。随 着有资金需求的小微企业数量不断增加, 银
行向小微企业贷款的收益率逐渐下降, 形成 长尾, 甚至出现负收益。银行自身经营的盈 利性目标自然使其拒绝向小微企业发放贷 款。因此, 小微企业是长尾理论中的长尾, 其资金需求构成了一个 “长尾” 市场。

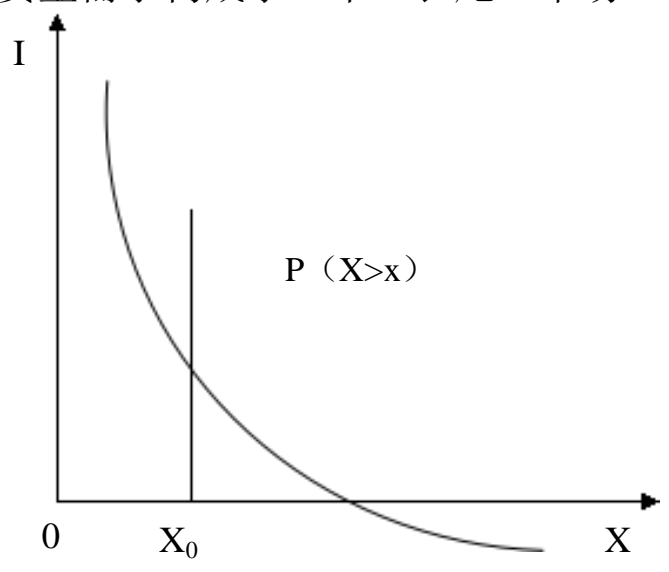

图 4 小微企业向银行贷款收益率

小微企业的资金需求构成一个长尾市 场, 为互联网金融的市场定位提供了一个方 向。互联网金融可以以长尾理论为基础, 开 发专门满足小微企业信贷需求的一种全新的 金融模式。传统商业银行竞相争取的 $20 \%$ 优 质客户虽能带来丰厚的利润，但由于数量有 限，竞争已十分激烈，互联网金融没有必要 参与到这种过度竞争中。相反, 传统商业银 行忽略的小微企业信贷市场供不应求, 具有 价值潜力。互联网金融可以利用自身优势, 既服务小微企业, 解决它们的信贷难题, 又 为自身谋取利润。

\section{3. 互联网金融助解小微企业信贷难的突破}

\section{1 互联网金融与准入限制}

传统商业银行的三性原则及小微企业自 身劣性共同导致了小微企业贷款难题。互联 网金融则对小微企业非常宽容，几乎没有准 入限制。任何有资金困难的小微企业都可以 通过互联网金融申请贷款。

互联网金融的无门槛还推动了普惠金融 的发展。不少网络融资平台对投资者的最低 投资要求仅 50 元、 100 元，让普通百姓也能 参与到金融活动中, 享受应有的金融服务。 大量民间资本浮出水面，开始实现阳光化、 规范化。 


\section{2 互联网金融与高效率}

由互联网支持的金融活动表现出极高的 效率：个人可以利用网络搜索引擎快速得到 所需要的各类市场信息。资金供需双方可以 直接在网上发布相关信息由交易平台进行匹 配。虽然最后的资金清算仍然通过银行进行, 但中间的支付环节不再经由银行, 且移动支 付不受时间和空间的限制。典型的 P2P 平台 拍拍贷, 企业从申请贷款到获得贷款仅需 3-7 天。

\section{3 互联网金融与信息不对称}

金融中介理论认为减少信息不对称和降 低交易成本的能力是传统商业银行吸收存 款、发放贷款的基础。然而, 在传统金融模 式下，信息是相对封闭的，由下向上单向传 递, 呈金字塔状 (如图 5 所示)。个体将信息 上报至 $\mathrm{B} 1, \mathrm{~B} 2$ 。 $\mathrm{B} 1, \mathrm{~B} 2$ 对信息进行加工之后 上传给 $A$ 。由于此过程中信息是单向传递的, 每次传递都必将丧失一部分真实信息。若经 过多层传递, 信息失真会更加严重。再者, 由于信息的封闭性、排他性，不同的信息接 受者都只得到了局部的信息而不能实现信息 共享。

国有企事业单位和大中型企业信息披露 到位, 信息公开、透明。小微企业规模小, 业务繁多, 信息高度内部化, 他们拥有的信 息必定比金融机构更加全面，这种信息上的 不对称使金融机构在贷款行为中处于不利地 位, 有可能导致逆向选择和道德风险。因此 传统商业银行不愿意轻易向小微企业提供贷 款。

在互联网金融模式下，信息的传播呈多 向、发散的网状结构 (如图 6 所示)。在这种 结构状态下，任何一点都能随时发出和获取 信息。以 $\mathrm{P} 2 \mathrm{P}$ 融资平台为例, 借款人直接在 平台上发布借款标，投资者通过网上搜索、 确认借款人并直接向借款人放贷。从贷款申 请到获取资金, 双方的身份信息、信用信息 都可以从平台上直接得到。合同的签署、资 金的到账也都通过网络实现，投资者可以从 融资平台上及时获得借款人的还款进度。信 息透明度高, 几乎不存在信息不对称。

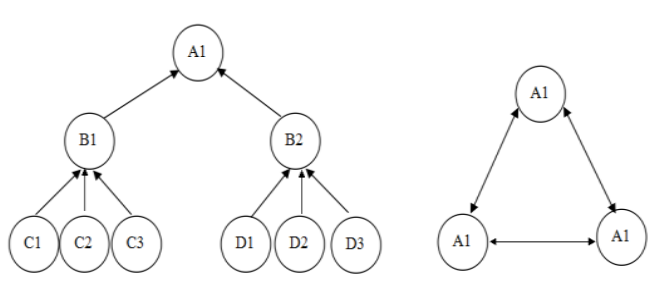

图 5 传统金融模式和互联网模式下的信息传递

\section{4 互联网金融与交易成本}

成本管理是长尾理论的关键因素, 若要 关注 “尾部” 市场并产生效益, 必须尽可能 降低关注成本。

从传统商业银行的贷款业务来看，不论 向谁放贷，商业银行所走的流程、所做的征 信工作都是一样的。小微企业规模小，单次 贷款金额不大，对其放贷经营成本较高。另 外, 小微企业不仅数量多, 而且差异性大, 若银行要发展小微企业贷款业务, 就必须增 加营业网点数量, 配备更多的设备和工作人 员，增加了经营成本。

互联网金融则大不相同。互联网金融的 绝大部分工作都在网络平台上进行，无需物 理意义上的营业网点, 免除了营业场所的费 用; 借助计算机系统自动分析数据, 省去了 传统柜台的人工费用。客户也无需为了申请 贷款奔波实体金融机构。

\section{5 互联网金融与小微企业的个性化需求}

小微企业数目众多, 经营类别千差万别, 对资金的数额、期限结构、利率要求也各不 相同。每个小微企业都有自己的金融需求特 征, 这种个性化的需求难以从传统银行业得 到满足。但是互联网金融依赖大数据、云计 算和搜索引擎，可以实现点对点的金融服务。 互联网金融可以根据小微企业客户的需要, 为他们量身定做金融产品，实现资金需求的 私人订制。

\section{4. 结束语}

综上所述，小微企业的资金需求形成了 长尾理论中的长尾市场。互联网金融定位长 尾市场, 利用自身优势降低了小微企业贷款 门槛, 提高了支付效率, 并能有效地减少信 息不对称，降低交易成本，满足小微企业的 个性化需求。尽管互联网金融只能从单个投 资者处吸收少量资金，但通过众多投资者的 
累积, 它可以汇集相当大的资金。此外, 互 联网金融与传统金融面对的是不同的客户 群, 是两种恰好形成互补的金融模式。

当前, 互联网金融已经衍生出众筹融资、 P2P 网络借贷平台、B2B 小额贷款等直接惠 及小微企业的形式。目前我国有股权众筹平 台 42 家, 涉及股权众筹项目 3876 个; P2P 平台 1946 家, 贷款余额 1932.14 亿元。此外, 阿里小贷作为小额贷款的代表, 已经为 70 多 万家小微企业累计放贷额 1700 多亿元, 且一 直将不良率保持在 $1 \%$ 以内。不难看出互联网 金融的巨大潜力和实力。

虽然互联网金融有诸多优势，但因监管 问题而受到诸多质疑。在此背景下, 互联网 金融机构应当做好行业自律, 加强自我约束, 自觉避开非法集资、借互联网金融搞资金池 等不法行为。央行和监管部门首先应当肯定 互联网金融在推动金融普惠方面的潜力和作 用, 其次应当加强监管, 尽快设立有关互联 网金融的法规, 及时发现互联网金融机构发 展过程中存在的问题, 为互联网金融的健康 发展保驾护航。新兴的互联网金融模式还处 于稚嫩期, 需要金融人的共同探索, 需要经 过时间和实践的沉淀和检验才能最终走向成 熟。

\section{References}

[1]. Zhang Ji. innovation policy of on-line banking in Chinese commercial bank [D].Capital University of Economics and Business

[2]. Xie Ping, Zou Chuan-wei. The Model Research of Internet Finance. Journal of Financial Research, Vol. 12, PP. 11-22,2012.

[3]. Wang Shu-guang, Zhang Chun-xia. the Chinese model and innovation of internet research[J]. Rural Credit Cooperative of China, Vol. 02, PP. 42-43, 2014.

[4]. Zhang Jie. review of the development of financial intermediation theory[J]. Social Science in China, Vol. 06, PP. 74-84, 2001.

[5]. Chen Li-dan, Huo Qian. long tail theory and spread of niche in Internet communication[J]. Southwest University for Nationalitiesjournal(humanities and social sciences), Vol. 04, PP. 148-152, 2013.

[6]. Yin Long. The development of financial innovation theory and regulation system[J]. Journal of Financial Research, Vol. 03, PP. 7-15,2005.

[7]. Wang Xin.internet finance helps to financing problem of small and micro business-based on the "long tail theory" [J]. Junal of Credit, Vol. 03, PP. 5-7, 2014.

[8]. Xue Qun-qun. the operation pattern and projects analysis of $\mathrm{P} 2 \mathrm{P}$ Microfinance companies in and out of China [D].Minzu University of China,2013.

[9]. Han Zhuang-fei. research of the development ofinternet finance [D].Henan University,2013.

[10]. Pi Tian-lei, Zhao Tie. Internet finance: logic, comparison and Mechanism [J]. Economic Issues in China, Vol. 04, PP. 98-108,2014.

[11]. Xie Tao. theanalysis of High-end customer relationshipmanagement in commercial bank [J]. Shandong Social Sciences, Vol. S2, PP. 66-68. 2011.

[12]. Liu Shi-yu.China's financial stability report 2014[R].Bei Jing.2014. 